\title{
$\mathrm{CaO}$ 첨가 $\mathrm{AZ31}$ 압출재의 개량된 미세조직이 인장, 고주기 피로 및 피로 균열 전파 특성에 미치는 영향 \\ 김영균 ${ }^{1} \cdot$ 김민종 ${ }^{2} \cdot$ 황유진 $^{1} \cdot$ 김세광 $^{3} \cdot$ 임현규 $^{3} \cdot$ 이기안 $^{1, *}$ \\ 1인하대학교 신소재공학과 \\ ${ }^{2} \mathrm{KCTL}$ \\ 3한국생산기술연구원
}

\section{Effect of Tailored Microstructures in CaO-Added AZ31 Extrusion Material on Tensile, High Cycle Fatigue and Fatigue Crack Propagation Properties}

\author{
Young-Kyun Kim ${ }^{1}$, Min-Jong Kim², Yu-Jin Hwang ${ }^{1}$, Shae. K. Kim ${ }^{3}$, Hyun-Kyu Lim ${ }^{3}$, and Kee-Ahn Lee ${ }^{1}$ * \\ ${ }^{I}$ Department of Materials Science and Engineering, Inha University, Incheon 22212, Republic of Korea \\ ${ }^{2}$ Korea Compliance Testing Laboratories Co., Yongin-si 17093, Republic of Korea \\ ${ }^{3}$ Korea Institute of Industrial Technology, Incheon 21999, Republic of Korea
}

\begin{abstract}
The effect of tailored microstructures in $0.5 \mathrm{wt} \% \mathrm{CaO}$ added AZ31 on tensile, high-cycle fatigue, and fatigue crack growth properties was examined. By adding $\mathrm{CaO}$, the average grain size (AGS) was significantly reduced from $4.25 \pm 2.32 \mu \mathrm{m}$ (conventional AZ31) to $2.42 \pm 1.60 \mu \mathrm{m}$ (CaO-AZ31). The fineprecipitates of CaO-AZ31 were more evenly distributed and their fraction was higher than those of conventional AZ31. The fine-precipitates were identified as $\mathrm{Al}_{8} \mathrm{Mn}_{4} \mathrm{Ca}$ and $(\mathrm{Mg}, \mathrm{Al})_{2} \mathrm{Ca}$ in $\mathrm{CaO}-\mathrm{AZ} 31$, meanwhile, were identified as $\mathrm{Al}_{8} \mathrm{Mn}_{5}$ and $\mathrm{Mg}_{17} \mathrm{Al}_{11}$ in conventional AZ31. The tensile test results showed that the yield strengths of CaO-AZ31 and conventional AZ31 were 238.0 MPa and 206.7 MPa, respectively. The elongation-to-failure also increased when $\mathrm{CaO}$ was added. The improved tensile properties of CaO-AZ31 could be explained by grain refinement and precipitation hardening. The high-cycle fatigue limit also increased about $15 \%$ with added $\mathrm{CaO}$. The fatigue limits as a function of the tensile strengths of CaO-AZ31 and conventional AZ31 were 0.508 and 0.457, respectively. The origin of the improved fatigue resistance was attributed to inhibition of the formation of DTs, which acted as the fatigue crack source, in CaO-AZ31. In contrast, the fatigue crack growth property did not change when $\mathrm{CaO}$ was added. Based on the above findings, the relationships between microstructure, mechanical properties and deformation mechanisms are also discussed.
\end{abstract}

(Received February 23 2021; Accepted March 30, 2021)

Keywords: AZ31, magnesium alloy, $\mathrm{CaO}$, microstructure, tensile, high cycle fatigue, fatigue crack propagation

\author{
1. 서 론 \\ 최근 온실 가스 방출 및 에너지 손실 등을 야기할 수 \\ 있는 산업계에서 저 비용, 우수한 비강도 및 낮은 에너지 \\ 손실을 충족하는, 지속가능한 소재 개발에 대한 관심이 증 \\ 가하고 있다 [1]. 이러한 문제점들을 극복하기 위한 하나의 \\ - 김영균: 박사 후 연구원, 김민종: 연구원, 황유진: 박사과정, 김세광.임현규: 박사, \\ 이기안: 교수 \\ ${ }^{*}$ Corresponding Author: Kee-Ahn Lee \\ [Tel: +82-32-860-7532, E-mail: keeahn@inha.ac.kr] \\ Copyright $(\mathcal{C}$ The Korean Institute of Metals and Materials
}

방안으로 저 융점을 가짐과 동시에 뛰어난 물리적-화학적 특성을 보이는 경량 금속들, 예를 들어 알루미늄 및 마그 네슘 합금에 대한 연구들이 광범위하게 이루어지고 있다 [2-4]. 경량 금속들 중 AZ31 마그네슘계 합금은 기존 철강 재료의 $1 / 5$ 수준, 알루미늄 합금의 $2 / 3$ 수준인 $~ 1.74{\mathrm{~g}-\mathrm{cm}^{-3}}^{-3}$ 의 비중을 가지며 이와 동시에 뛰어난 비강도를 나타낸다 [5]. 또한, 우수한 주조성, 및 진동 감쇠능 등의 여러 장점 을 가져 경량 구조 부품용 소재로서 많은 관심을 받고 있 다 [5-7].

그러나 마그네슘 합금은 조밀 육방(hexagonal close 
packed, HCP) 구조를 가지기 때문에 가공성이 떨어지며, 이는 마그네슘 합금의 개발 및 응용을 방해하는 요인으로 작용한다 [8]. 따라서, 다양한 합금 원소를 마그네슘에 첨 가함으로써 비기저 슬립 시스템(non-basal slip system)의 임계 분해 전단 응력(critical resolved shear stress, $\mathrm{CRSS}$ )을 낮춰 성형성을 향상시키려는 노력이 진행되어 왔 다 [9-11]. 이와 함께 반용융 압출 기법을 통해 집합 조직 생성을 억제함과 동시에 미세 결정립을 제어하여 상온 성 형성을 향상시키는 연구가 보고되고 있다 [12]. 그러나, 이 와 같은 노력에도 불구하고 마그네슘 합금을 고성능이 요 구되는 부품에 적용하기에는 많은 어려움이 있으며, 그 요 인 중 하나는 상기 방법들을 이용할 경우 부품의 최종 단 가가 매우 비싸다는 점이다.

따라서 최근에는 희토류 원소들과 유사한 특징을 보이지 만 상대적으로 저렴한 $\mathrm{Ca}$ 원소를 마그네슘 합금에 첨가하 여 소재의 성능을 향상시키려는 연구들이 수행된 바 있다 [13-15]. 특히 $\mathrm{Ca}$ 은 $\mathrm{Mg}-\mathrm{Al}$ 합금들에서 기계적 특성을 향 상시킴과 동시에 산화 저항성을 개선할 수 있는 것으로 보 고되고 있어 그 관심이 증가하고 있다 [13-15]. 그러나, $\mathrm{Ca}$ 원소 그 자체로 첨가할 경우 고온 균열을 야기시킬 수 있기 때문에 새로운 방안들이 모색되고 있으며, 최근 Seo 등은 [16]은 마그네슘 합금에 $\mathrm{Ca}$ 대신 $\mathrm{CaO}$ 를 첨가함으로 써 상기 문제점의 해결 방안을 제시하였다. 마그네슘 합금 에 $\mathrm{CaO}$ 를 첨가할 경우 용탕 표면에 안정적인 슬래그를 형성함으로써 $\mathrm{SF}_{6}$ 와 같은 온실 가스의 사용을 극적으로 감 소시킬 수 있으며, 환경 및 인체에 악 영향을 미치는 $\mathrm{SO}_{2}$ 가스를 사용하지 않을 수 있다 [16]. 이와 함께 $\mathrm{CaO}$ 첨가 는 결정립 및 석출상을 미세화시키고 기계적 특성을 개선 할 수 있는 것으로 보고된 바 있다 [17]. 이러한 많은 장 점들이 존재함에 불구하고 현재까지 $\mathrm{CaO}$ 를 첨가한 $\mathrm{AZ} 31$ 합금의 연구는 아직 부족한 실정이다. $\mathrm{CaO}$ 첨가 $\mathrm{AZ31}$ 에 대한 대부분의 연구는 변형률 속도에 따른 집합 조직 변화 [18], 고온 성형성 [19], 및 미세조직 변화 [20]에 대한 연 구만이 수행되었다. 그러나, 실제 $\mathrm{CaO}$ 첨가 $\mathrm{AZ31}$ 을 지속 가능한 경량 구조용 부품으로 이용하기 위해서는 구조 부 품 파괴의 대부분을 차지하는 고주기 피로 특성에 대한 연 구가 필수적으로 요구된다. 이와 함께, 실제 부품으로 이용 될 시 $\mathrm{CaO}$ 첨가가 $\mathrm{AZ31}$ 의 피로 균열 전파 거동에 미치 는 영향에 대한 연구도 제시되어야 하지만 현재까지 관련 된 연구가 전혀 보고된 바 없다.

본 연구에서는 $0.5 \mathrm{wt} \% \mathrm{CaO}$ 첨가 $\mathrm{AZ} 31$ 을 제조하고 이 에 대한 미세조직 및 기계적 특성(인장, 고주기 피로, 피로 균열 전파)을 상용 $\mathrm{AZ31}$ 합금과 비교 분석하였다. 이와
함께, 초기 미세조직적 특징의 차이를 기반으로 인장, 고주 기 피로 및 피로 균열 전파 기구들을 고찰하였다.

\section{2. 실험 방법}

본 연구에서는 상용 마그네슘 $\mathrm{AZ31}(\mathrm{Mg}-3 \% \mathrm{Al}$ $0.9 \% \mathrm{Zn}$ ) 합금과 $0.5 \mathrm{wt} \% \mathrm{CaO}$ 가 첨가된 $\mathrm{AZ31}$ (편의를 위 하여 $\mathrm{CaO}-\mathrm{AZ} 31$ 로 명명)을 5 인치 빌렛으로 제조한 뒤 $80 \mathrm{~mm} \times 15 \mathrm{~mm}$ 로 압출하였다. 두 소재들의 분석된 화학 조성들은 표 1 에 정리하였다. 제조된 두 소재들의 미세조 직 분석을 위해 silicon carbide 페이퍼(\#400 \#2000)로 연마 후 $1 \mu \mathrm{m}$ 크기의 다이아몬드 현탁액(diamond suspension)으

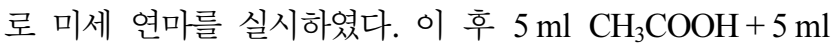
$\mathrm{H}_{2} \mathrm{O}+35 \mathrm{ml} \mathrm{C}_{2} \mathrm{H}_{5} \mathrm{OH}+2.1 \mathrm{~g}$ picric acid로 이루어진 에칭 액을 사용하여 시편을 에칭한 뒤 미세조직을 분석하였다. 미세조직 분석은 주사 전자 현미경(scanning electron microscope, SEM, VEGA II LMU, TESCAN), X-선 회절 분석기(X-ray diffractometer, XRD, Ultima IV, Rigaku), 에 너지 분산형 분광 분석(energy dispersive spectroscopy, $\mathrm{EDS})$, 전자 탐침 미세 분석기(electron probe micro analyzer, EPMA, EPMA-1600, Shimadzu)를 이용하여 진 행하였다.

인장 시편은 ASTM E8M 표준 시험편을 이용했으며, 10 톤 용량의 만능 재료 시험기(Instron 8501, Instron)를 사용하여 인장 시험을 상온에서 수행하였다. 초기 변형률 속도 (strain rate)는 $1 \times 10^{-3} \mathrm{~s}^{-1}$ 으로 설정했으며 데이터의 신뢰성을 확보하기 위해 각 시험편에 대해 최소 3 번의 인장 시험을 수행한 뒤 대표적인 값을 사용하였다. 고주기 피로 시험의 경우 게이지 길이 $20 \mathrm{~mm}$ 및 $\Phi 12 \mathrm{~mm}$ 크 기를 가지는 ASTM E466 표준 봉상 시험편을 이용하여 실험을 진행했으며, 고주기 피로 시험 전 silicon carbide 페이퍼 \#2000로 표면 연마 후 실험을 수행하였다. 고주기 피로 시험에 대한 응력 비 $R$ 은 0.1 로, 주파수는 $20 \mathrm{~Hz}$ 로 설정했으며 $10^{7}$ 사이클 도달까지 파괴가 일어나지 않는 응 력을 피로 한계(fatigue limit)로 판단하였다. 피로 균열 전 파 시험의 경우 ASTM E647 표준 시험편(micro compact tension, Micro-CT)을 이용하여 응력비 $R$ 은 0.1 , 주파수

Table 1. Chemical compositions of conventional AZ31 and CaOAZ31 alloys used in this study (unit: wt\%).

\begin{tabular}{lcccccc}
\hline Composition & $\mathrm{Al}$ & $\mathrm{Zn}$ & $\mathrm{Si}$ & $\mathrm{Ca}$ & $\mathrm{Mn}$ & $\mathrm{Mg}$ \\
\hline Conventional AZ31 & 2.293 & 0.665 & 0.081 & - & 0.256 & $\mathrm{Bal}$. \\
$\mathrm{CaO}-\mathrm{AZ31}$ & 2.411 & 0.796 & 0.122 & 0.500 & 0.384 & $\mathrm{Bal}$.
\end{tabular}


$10 \mathrm{~Hz}$ 조건으로 실험을 진행하였다.

\section{3. 실험 결과 및 고찰}

\section{1 미세조직}

그림 1은 상용 $\mathrm{AZ31}$ 과 $\mathrm{CaO}$ 첨가 $\mathrm{AZ31}$ 의 초기 미세 조직들에 대한 SEM 사진들을 보여준다. 그림에서 나타나 는 것과 같이 상용 $\mathrm{AZ31}$ 의 경우 불 균일한 결정립 분포 를 보였으며 평균 결정립 크기는 $4.25 \pm 2.32 \mu \mathrm{m}$ 이었다(그 림 1a). 이와 달리 $\mathrm{CaO}-\mathrm{AZ3} 3$ 은 상용 $\mathrm{AZ} 31$ 과 비교하여 상대적으로 균일한 결정립 분포를 가지며, 평균 결정립 크 기는 $2.42 \pm 1.60 \mu \mathrm{m}$ 로 확인되었다(그림 $1 \mathrm{~b}$ ). 이는 $\mathrm{CaO}$ 첨 가만을 통해 동일한 제조 조건에서 상대적으로 균일하고 미세한 결정립 크기를 제어할 수 있음을 의미한다. 이와 함 께, 두 소재들에서 $\mathrm{CaO}$ 첨가에 따라 석출상의 분율 및 분포 역시 크게 변화하는 것으로 나타났다. 상용 AZ31의 경우 상들이 조대하게 형성된 반면, $\mathrm{CaO}-\mathrm{AZ3} 1$ 의 경우 미 세한 석출상들이 고르게 분포하고 있는 형태를 보였다. Son 등 [20]은 $\mathrm{AZ31}$ 에 $\mathrm{CaO}$ 를 첨가하게 되면 $\mathrm{Ca}$ 관련 금속간 화합물, 예를 들면 $\mathrm{Al}_{2} \mathrm{Ca}(\mathrm{C} 15),(\mathrm{Al}, \mathrm{Mg})_{2} \mathrm{Ca}$ 및 $\mathrm{Al}_{8} \mathrm{Mn}_{4} \mathrm{Ca}$, 들이 $\mathrm{Mg}$ 기지에서 석출될 수 있다고 보고 하였다. 여기서 Son 등 [20]은 새로운 석출상들의 형성은 $\mathrm{CaO}$ 가 $\mathrm{Ca}$ 로 분해되고 고상 상태에서 $\mathrm{Mg}$ 기지와 반응함 에 따라 나타난 결과임을 제시하였다 [20]. 즉, $\mathrm{CaO}$ 첨가 함으로써 결정립 미세화를 유도함과 동시에 석출 상을 미 세하고 고르게 분포시킬 수 있다.

두 소재들에 존재하는 상들을 분석하기 위하여 X-선 회 절 분석을 수행했으며 그 결과를 그림 2에 도시하였다. 그 림에 나타나는 것과 같이 두 소재들에서 모두 $\alpha-\mathrm{Mg}$ 이 주 된 상으로 검출되었으며 $\mathrm{Cl}, \mathrm{Al}_{8} \mathrm{Mn}_{5}$ 및 $\mathrm{Mg}_{17} \mathrm{Al}_{12}$ 와 같 은 상들이 추가적으로 확인되었다. $\mathrm{CaO}$ 를 첨가함에 따라 $\alpha-\mathrm{Mg}$ 의 변화는 크게 관찰되지 않았으나, $\mathrm{Al}_{8} \mathrm{Mn}_{5}$ 상의 피

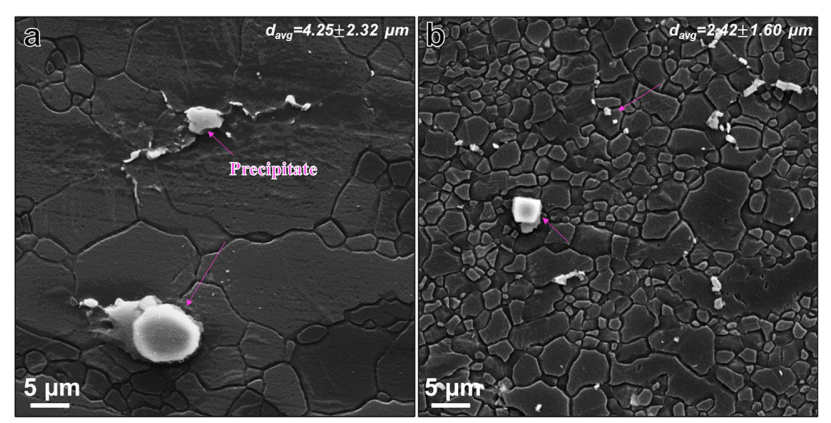

Fig. 1. SEM micrographs showing the as-extruded microstructures of (a) conventional AZ31 and (b) CaO-AZ31 alloys.

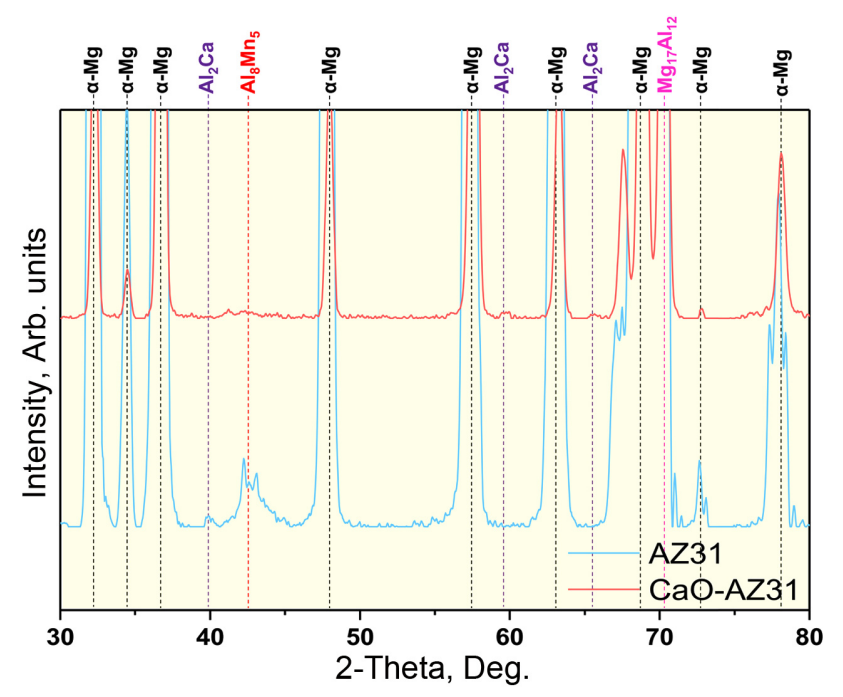

Fig. 2. X-ray diffraction analysis results of conventional AZ31 and CaO-AZ31 alloys.

크 강도가 감소하였고 반면 $\mathrm{C} 15$ 상의 피크가 추가적으로 검출되었다. 이를 통해 $\mathrm{CaO}-\mathrm{AZ} 31$ 의 결정립계에서 다량 석출되었던 상은 $\mathrm{C} 15$ 로 예상할 수 있었다.

추가적인 상 분포를 확인하기 위하여 EPMA 원소 분포 맵을 분석했으며 그 결과를 그림 3에 도시하였다. 여기서 $\mathrm{a}$ 는 상용 $\mathrm{AZ31}$ 그리고 $\mathrm{b}$ 는 $\mathrm{CaO}$ 가 첨가된 $\mathrm{AZ31}$ 의 $\mathrm{EPMA}$ 분석 결과들이다. 먼저 상용 AZ31 합금의 EPMA 결과를 살펴보면 (그림 $3 \mathrm{a}$ ), 석출물의 분율은 약 $0.48 \%$ 로 측정되었다. 이와 함께 $\mathrm{Al}$ 원소가 특정 영역을 따라 편석 되고 이러한 영역에서 $\mathrm{Mg}$ 의 고갈이 나타났다. 한편, 대부 분의 석출물에서는 $\mathrm{Al}$ 과 $\mathrm{Mn}$ 원소들이 함께 높은 밀도로 존재했으며, 앞선 $\mathrm{EPMA}$ 와 $\mathrm{XRD}$ 분석 결과들을 고려해 볼 때, 그 상이 $\mathrm{Al}_{8} \mathrm{Mn}_{5}$ 임을 유추할 수 있었다. 또한, $\mathrm{Mg}$ 및 $\mathrm{Al}$ 원소들이 높게 나타난 석출물이 추가적으로 관 찰되었으며 이는 $\mathrm{Mg}_{17} \mathrm{Al}_{12}$ 로 사료된다. 즉, 상용 $\mathrm{AZ31}$ 은 주로 $\mathrm{Mg}_{17} \mathrm{Al}_{12}$ 및 $\mathrm{Al}_{8} \mathrm{Mn}_{5}$ 석출물이 존재하는 것을 알 수 있었다. 반면 $\mathrm{CaO}-\mathrm{AZ} 31$ 은 상용 $\mathrm{AZ} 31$ 보다 높은 석출물 분율 ( 1.02\%)을 나타냈으며, 이와 함께 석출물이 고르게 분포하는 특징을 보였다. 대부분의 석출물에서는 $\mathrm{Ca}$ 이 존 재하는 특징을 보였으며, 이전 보고된 연구 결과들을 바탕 으로 $\mathrm{Mn}$ 과 동시에 존재하는 상은 $\mathrm{Al}_{8} \mathrm{Mn}_{4} \mathrm{Ca}$, 그리고 $\mathrm{Mg}-\mathrm{Al}$ 과 동시에 존재하는 상은 $\left(\mathrm{Mg}, \mathrm{Al}_{2} \mathrm{Ca}(\mathrm{C} 15)\right.$ 으로 예상할 수 있었다. 여기서 $\mathrm{Al}_{2} \mathrm{Ca}$ 가 아닌 $\left(\mathrm{Mg}, \mathrm{Al}_{2} \mathrm{Ca}\right.$ 로 존재하는 것은 $\mathrm{Mg}$ 원소가 $\mathrm{Al}$ 의 자리를 치환할 수 있기 때문으로 사료된다. 상기 $\mathrm{SEM}, \mathrm{XRD}$ 및 $\mathrm{EPMA}$ 분석 결 과들을 통해 $\mathrm{AZ} 31$ 에 $\mathrm{CaO}$ 를 첨가할 경우 $\mathrm{Ca}$ 가 분해됨과 


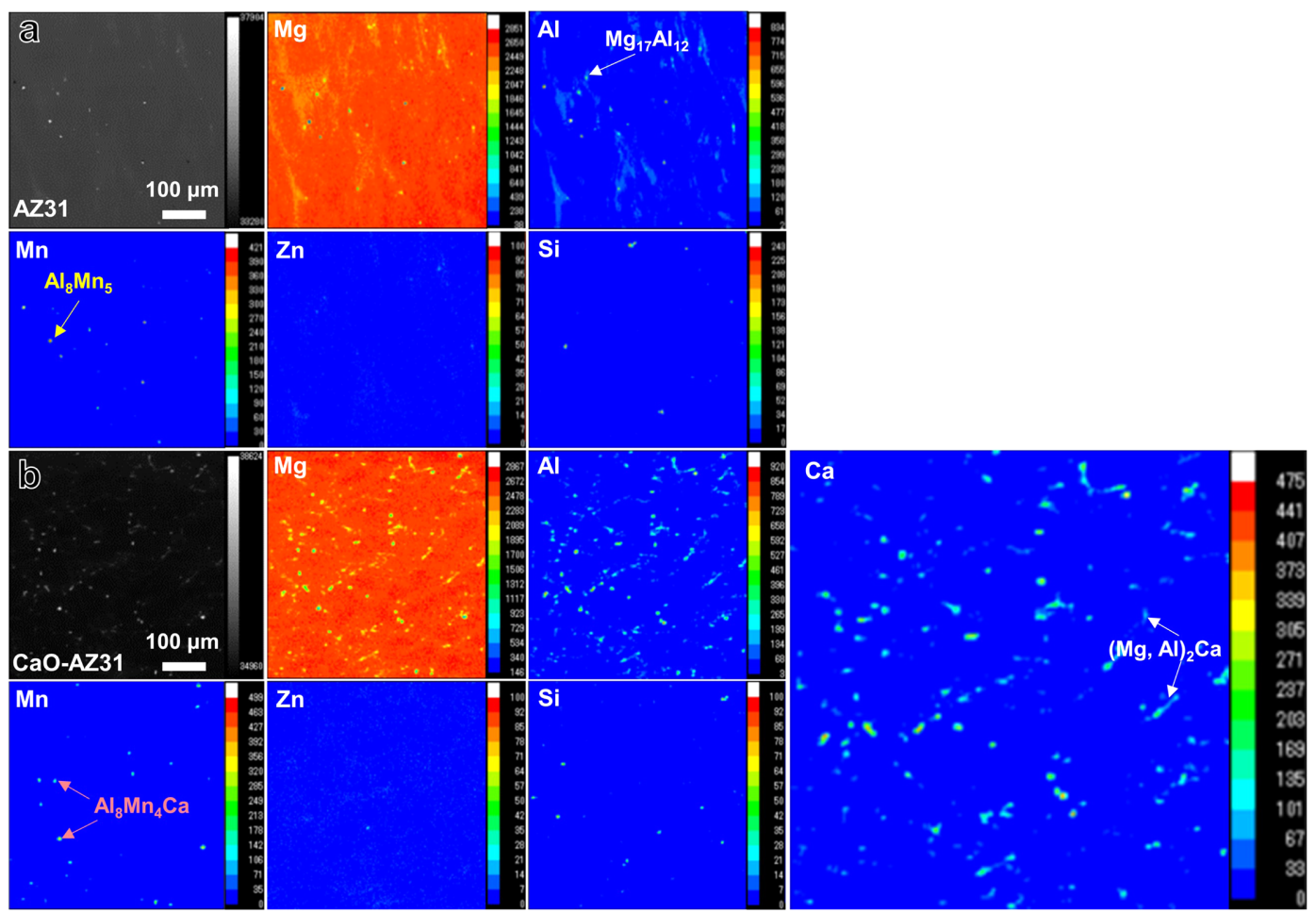

Fig. 3. EPMA elemental distribution maps of (a) conventional AZ31 and (b) CaO-AZ31 alloys.

동시에 효과적으로 미세하고 고른 석출물을 형성시키는 것 으로 확인되었다. 이러한 미세하고 고른 석출물 분포는 결 정립 미세화와도 관련 있을 것으로 예상된다. 그러나, 현재 까지 $\mathrm{Ca}$ 원소가 $\mathrm{Mg}$ 기지에서 어떻게 결정립 미세화를 가 능케하는지에 대한 원인은 명확히 제시되지 않았다. Zeng 등 [21]은 결정립 미세화와 관련하여 다음의 두 가지 요인 들을 고려하였다: 1) 용질 효과, 2) 석출물 효과. 먼저 용 질 효과와 관련하여 성장 억제 인자 (growth restriction factor, GRF)가 고려될 수 있으며 GRF가 높을수록 결정립 성장을 억제하는 것으로 보고되었다 [21]. $\mathrm{Ca}$ 은 $\mathrm{Mg}$ 기지 에서 11.94 의 $\mathrm{GRF}$ 값을 가지며 이는 $\mathrm{Mg}$ 합금에서 이용 되는 통상적인 합금 원소들 중 가장 높은 $\mathrm{GRF}$ 값이다. 즉, $\mathrm{CaO}$ 가 $\mathrm{AZ} 31$ 기지에서 $\mathrm{Ca}$ 로 분해되어 일부 용질 상 태로 존재하게 되면 결정립 미세화를 유도하는 것으로 사 료된다. 이와 함께, $\mathrm{Ca}$ 은 $\mathrm{AZ} 31$ 기지내에서 용질 원소로 존재하는 것뿐만 아니라 응고 중 $\mathrm{C} 15$ 상으로 변화될 수 있다. 이러한 C15 상이 석출되면 Zener pressure를 발생 시킴에 따라 결정립 성장을 억제할 수 있다.

\section{2 인장 특성}

그림 4는 상용 $\mathrm{AZ} 31$ 과 $\mathrm{CaO}-\mathrm{AZ3} 1$ 의 상온 인장 결과들 을 보여준다. 먼저, 인장 응력-변형률 곡선을 살펴보면 (그
림 4(a)), 상용 $\mathrm{AZ31}$ 및 $\mathrm{CaO}-\mathrm{AZ31}$ 의 항복 강도(yield strength, $\sigma_{\mathrm{y}}$ )들은 각각 $206.7 \mathrm{MPa}$ 및 $238.0 \mathrm{MPa}$ 로 측정 되어, $\mathrm{CaO}$ 첨가에 따라 항복 강도가 약 $15 \%$ 상승하는 것 으로 나타났다. 이와 함께 최대 인장 강도(ultimate tensile strength, $\sigma_{\mathrm{UTS}}$ ) 역시 $\mathrm{CaO}$ 를 첨가한 $\mathrm{AZ31}$ 이 $314.6 \mathrm{MPa}$ 로 상용 AZ31의 최대 인장 강도(306.3 MPa)보다 우수한 특 성을 보였다. 그 원인들 중 우선 Hall-Petch 관계식에 따 라 상대적으로 미세한 결정립을 갖는 $\mathrm{CaO}-\mathrm{AZ31}$ 이 뛰어난 기계적 특성을 가지는 것으로 사료된다. 추가적으로 높은 석출물의 분율 역시 기계적 특성 향상에 긍정적인 영향을 미친 것으로 생각된다. 그림 4(b)는 두 소재들의 진 응력변형률 곡선들 및 가공 경화율(work hardening rate, $\mathrm{WHR}$ ) 곡선들이다. 그림을 살펴보면 $\mathrm{CaO}-\mathrm{AZ31}$ 이 상용 $\mathrm{AZ31}$ 과 비교하여 모든 소성 변형율에서 상대적으로 더 높 은 유동 응력(flow stress)을 보여준다. 그러나, 가공 경화 율을 비교해보면 상용 $\mathrm{AZ31}$ 이 $\mathrm{CaO}-\mathrm{AZ} 31$ 보다 높은 것으 로 확인되었다. 이러한 원인은 $\mathrm{AZ31}$ 의 일반적인 변형 거 동과 관련된 것으로 예상된다. AZ31의 경우 인장 변형 중 다량의 변형 쌍정(deformation twin)이 형성될 수 있으며, 생성된 쌍정 계면들은 결정립계와 동일하게 전위의 이동을 억제하는 역할을 한다 [22]. 즉, $\mathrm{AZ31}$ 의 높은 가공 경화 율은 변형 쌍정에 기인하는 것으로 설명될 수 있다. 반면, 

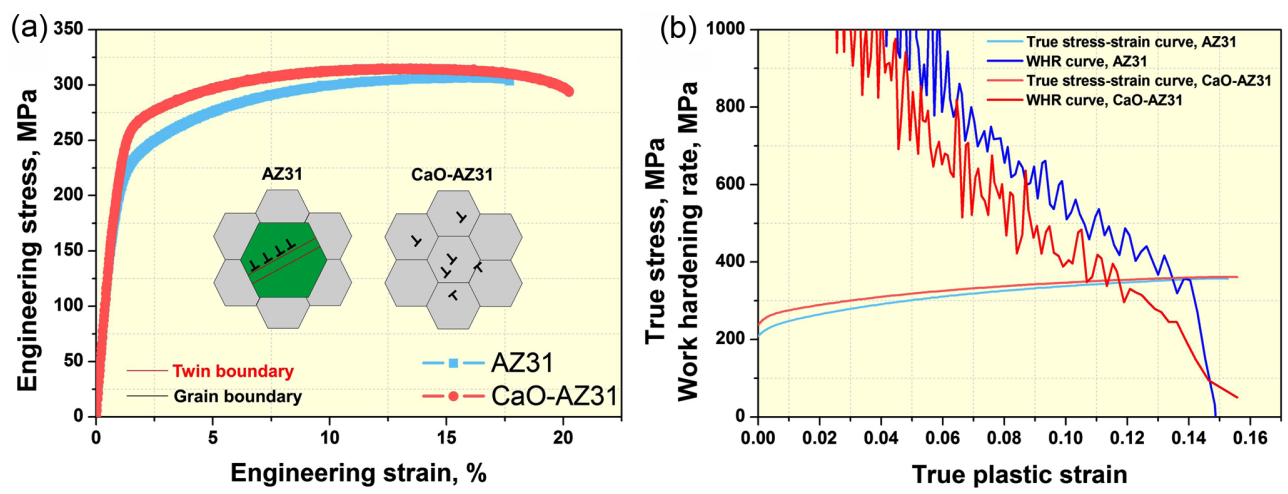

Fig. 4. (a) Typical tensile stress-strain curves and (b) True stress-strain and work hardening rate curves of both alloys. Inset in Fig. 4(a) represents the different deformation behavior between conventional AZ31 and CaO-AZ31 alloys.

$\mathrm{CaO}-\mathrm{AZ} 31$ 의 경우 미세한 결정립 크기를 가지기 때문에 변형 쌍정의 형성이 어려울 수 있다. 일반적으로, 변형 쌍 정의 생성은 결정립 크기와 반 비례 관계를 가지며, 미세 결정립을 가질 경우 변형 쌍정 생성에 필요한 활성화 응력 (activation stress for twinning)이 급격히 증가하는 것으로 알려져 있다 [23]. 즉, $\mathrm{CaO}-\mathrm{AZ3} 3$ 은 상용 $\mathrm{AZ31}$ 과 비교하 여 결정립 크기가 작아 변형 쌍정을 쉽게 생성하지 못하고 이로 인해 가공 경화율이 낮은 것으로 사료된다. 한편, 그림 4(a)에 나타난 연신율의 차이(AZ31: $16.5 \%, \mathrm{CaO}-\mathrm{AZ} 31$ : $19.0 \%$ 역시 변형 쌍정 생성 거동의 차이에 의해 설명될 수 있다. Zhao 등 [24]은 $\mathrm{Mg}$ 합금이 불균일한 결정립 크 기를 가질 경우 인장 변형 중 조대 결정립에서 집중적으로 변형 쌍정이 생성되는 것을 확인한 바 있다. 이러한 변형 쌍정은 전위의 핵 생성 위치로 작용할 수 있으며 그림 4의 삽도에 나타낸 것과 같이 변형은 특정 영역에 더욱 집중된 다. 그 결과, 조대 결정립에서 균열이 더 쉽게 생성될 수 있으며 이에 따라 상용 $\mathrm{AZ} 31$ 이 $\mathrm{CaO}-\mathrm{AZ} 31$ 과 비교하여 상 대적으로 낮은 연신율을 가지는 것으로 이해될 수 있다.

그림 5는 두 소재의 인장 파단면을 보여준다. 먼저 상용

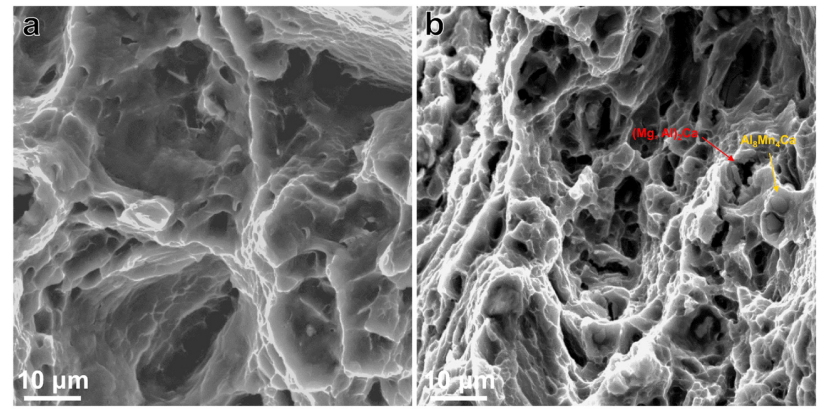

Fig. 5. SEM micrographs of tensile fractured surfaces of (a) conventional AZ31 and (b) CaO-AZ31 alloys.
AZ31의 경우 연성 파괴의 전형적인 특징인 딤플(dimples) 들이 관찰되었으나, 일부 영역에서 준 벽개 파괴(quasicleavage fracture) 형태를 나타냈다. 이는 앞서 설명한 것 과 같이 조대 결정립 영역에서 변형 쌍정 형성에 따라 변 형이 집중되어 발생한 것으로 사료된다. 반면, $\mathrm{CaO}-\mathrm{AZ} 31$ 의 경우 모든 영역에서 상대적으로 균일한 딤플에 의한 연 성 파괴를 보였다. 이와 함께, 딤플 내부에서는 $\mathrm{C} 15$ 상과 $\mathrm{Al}_{8} \mathrm{Mn}_{4} \mathrm{Ca}$ 상이 관찰됨에 따라 이들이 효과적인 강화상 역 할을 하는 것을 알 수 있었다.

\section{3 고주기 피로 특성}

그림 6은 두 소재들의 고주기 피로 시험에 따른 응력-수 명 $(\mathrm{S}-\mathrm{N})$ 곡선들을 보여준다. 고주기 피로 시험 결과, 상 용 $\mathrm{AZ31}$ 및 $\mathrm{CaO}-\mathrm{AZ31}$ 의 피로 한도(fatigue limit, $\sigma_{\mathrm{f}}$ )들 은 각각 $140 \mathrm{MPa}$ 및 $160 \mathrm{MPa}$ 로 확인되어 $\mathrm{CaO}$ 첨가에

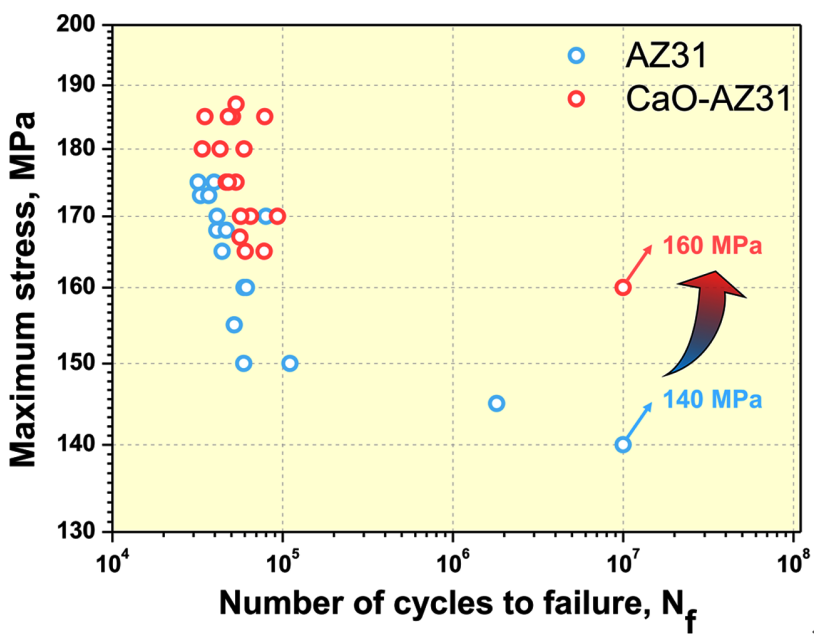

Fig. 6. The S-N high cycle fatigue curves of both AZ31 alloys (each arrow indicates the fatigue limit). 


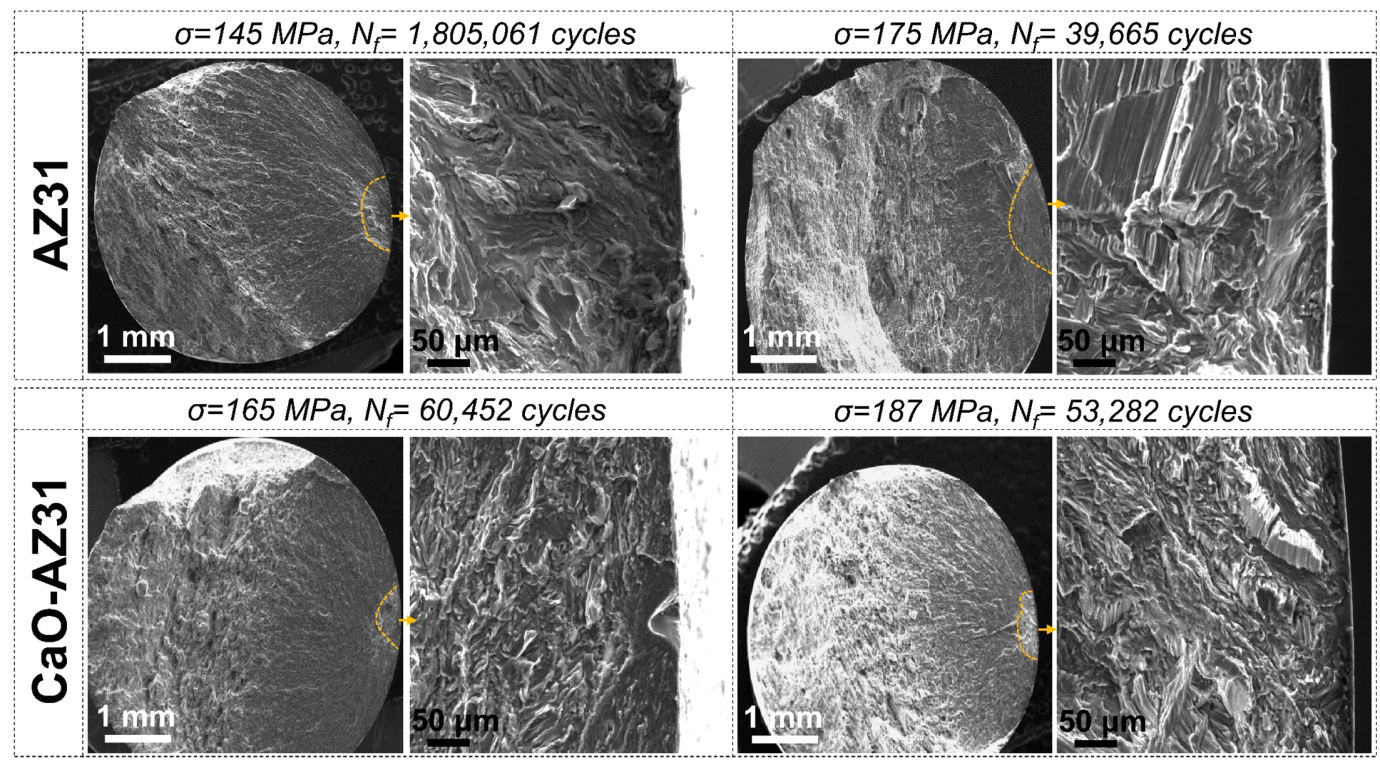

Fig. 7. Typical fractographies of the fatigue-fractured conventional AZ31 and CaO-AZ31 alloys.

따라 항복 강도와 동일하게 약 $15 \%$ 피로 한도가 증가하 였다. 일반적으로 고 주기 피로 저항성을 판단하는 기준으 로써 인장 강도 대비 피로 한도 $\left(\sigma_{\mathrm{f}} / \sigma_{\mathrm{UTS}}\right)$ 가 이용될 수 있 다. 두 소재의 $\sigma_{\mathrm{f}} / \sigma_{\mathrm{UTS}}$ 을 계산해 본 결과, 상용 $\mathrm{AZ31}$ 및 $\mathrm{CaO}-\mathrm{AZ} 31$ 에서 각각 $0.457,0.508$ 로 얻어져 $\mathrm{CaO}$ 첨가에 따라 피로 저항성이 개선되는 것을 알 수 있었다.

고주기 피로 저항성이 향상된 원인을 분석하기 위하여 먼저 피로 파단면들을 관찰했으며 그 결과를 그림 7에 나 타냈다. 모든 응력 범위에서 두 소재들의 피로 균열 생성 은 시편의 표면으로부터 시작하는 것을 알 수 있었다. 이 를 통해 표면 부위에서 전위의 이동에 의해 발생한 영구 슬립 밴드(persistent slip band, PSB)가 피로 균열 생성원 으로 예상할 수 있었다. 한편, 피로 균열 생성 영역에 대 한 확대 이미지를 살펴보면 상용 $\mathrm{AZ} 31$ 에 비해 $\mathrm{CaO}$ $\mathrm{AZ31}$ 이 상대적으로 거친 형태를 보였다. 이는 $\mathrm{CaO}$ 를 첨 가할 경우 특정 벽개면을 따라 피로 균열이 쉽게 생성-전 파되는 것이 억제되는 것을 의미한다. 이러한 피로 균열 생성 원인을 이해하기 위하여 피로 파단 시편들의 단면들 을 분석하고 그 결과를 그림 8 에 도시하였다. 먼저 상용 $\mathrm{AZ31}$ 의 피로 단면을 관찰한 결과(그림 $8 \mathrm{a}_{1}$ ), 피로 손상 (damage) 영역과 파괴(fracture) 영역이 뚜렷하게 구분되었 다. 이와 함께, 피로 균열 시작점을 확대해 본 결과(그림 $\left.8 \mathrm{a}_{2}\right)$, 균열 시작점에서 쌍정이 다량 관찰되었다. $\mathrm{CaO}$ $\mathrm{AZ31}$ 의 피로 단면 관찰 결과(그림 $8 \mathrm{~b}_{1}$ ), 상용 $\mathrm{AZ31}$ 과 동 일하게 피로 데미지 및 파괴 영역이 뚜렷하게 구분되어 나

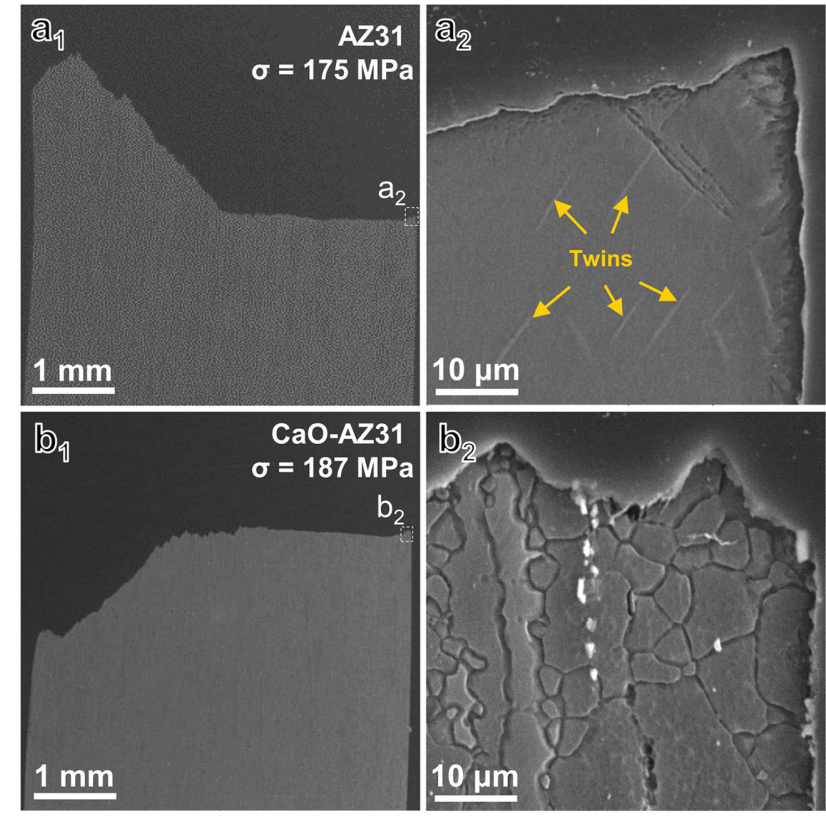

Fig. 8. Cross-sectional SEM micrographs of fatigue tested samples. $\left(\mathrm{a}_{1-2}\right)$ conventional AZ31 and $\left(\mathrm{b}_{1-2}\right) \mathrm{CaO}-\mathrm{AZ} 31$ alloys.

타났다. 그러나, 균열 시작점을 확대해보면(그림 $8 \mathrm{~b}_{2}$ ), 균열 시작점에서 어떠한 균열이나 쌍정은 관찰되지 않았으며, 이 는 $\mathrm{CaO}$ 첨가에 의해 감소된 결정립 크기가 변형 쌍정 생 성에 필요한 활성화 응력을 증가시키기 때문으로 사료된다. 일반적으로, $\mathrm{Mg}$ 합금의 경우 상온에서 작동하는 독립적인 슬립 계(slip system)는 두 개 이기 때문에, 일축 하중 기 


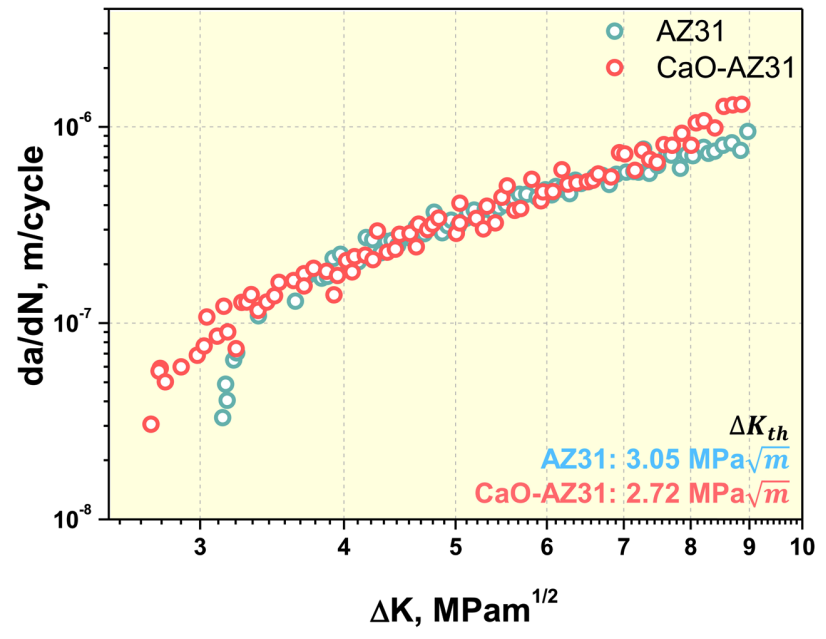

Fig. 9. The da/dN- $\Delta K$ fatigue crack propagation curves of conventional AZ31 and $\mathrm{CaO}-\mathrm{AZ} 31$ alloys.

반 피로 시험 중 변형 쌍정이 충분히 형성될 수 있다 [25]. 이때 변형 쌍정 형성으로 인해 슬립이 용이해지고 그 결과 전위들이 특정 쌍정 면에 집적될 수 있으며, 이는 피 로 특성의 저하를 유도한다. Lee 등[25]은 AZ80 및 TAZ711 Mg 합금들에 대하여 고주기 피로 시험을 수행하 였다. 그 결과 TAZ711 합금이 AZ80보다 높은 항복 강도 를 가짐에도 불구하고 조대한 미재결정된 결정립들이 존재 함에 따라 피로 시험 중 변형 쌍정이 생성되어 피로 저항 성이 감소하였다. 상기 결과들을 고려해볼 때, 상용 AZ31 의 경우 균열 시작점에서 다량의 변형 쌍정이 생성된 반면 $\mathrm{CaO}-\mathrm{AZ} 31$ 은 변형 쌍정이 전혀 관찰되지 않은 것을 통해 $\mathrm{CaO}$ 첨가에 따른 결정립 미세화는 인장 특성뿐만 아니라 고주기 피로 저항성 향상에도 긍정적인 역할을 하는 것으 로 사료된다.

\section{4 피로 균열 전파 특성}

$\mathrm{Mg}$ 합금의 경우 실제 항공기 및 구조용 부품으로 적용 되기 위해서는 고주기 피로 특성과 동시에 피로 균열 전파 거동에 대한 이해도 중요하다. 상용 AZ31 및 $\mathrm{CaO}-\mathrm{AZ} 31$ 의 피로 균열 전파 시험들을 수행하고 그 결과를 그림 9 에 도시하였다. 피로 균열 전파 시험 수행 결과, 두 소재 들에서 균열 전파 거동의 큰 차이는 나타나지 않았다. 일 반적으로 피로 균열 전파 속도 $(\mathrm{da} / \mathrm{dN})$ 과 응력 확대 계수 범위 $(\Delta K)$ 와의 관계는 Paris 수식으로 나타낼 수 있으며 다음과 같다 [26].

$$
\frac{d a}{d N}=\mathrm{C}(\Delta K)^{m}
$$

여기서 $\mathrm{m}$ 은 응력 확대 계수 범위 $(\Delta K)$ 와 피로 균열 전 파 속도 $(\mathrm{da} / \mathrm{dN})$ 의 $\log$ 기울기에 해당하는 Paris 지수이며, $\mathrm{m}$ 값이 클수록 피로 균열 전파 속도는 응력 확대 계수에 따라 민감한 것을 의미한다. $\mathrm{CaO}-\mathrm{AZ} 31$ 의 $\mathrm{m}$ 값은 1.72 로 나타난 반면 상용 $\mathrm{AZ31}$ 은 1.36 으로 얻어졌다. 즉, $\mathrm{CaO}$ 첨가에 따라 $\Delta K$ 에 대한 피로 균열 전파 속도가 더욱 민 감하게 반응하는 것을 알 수 있었다. 이와 함께, 임계 응 력 확대 계수 범위(near-threshold $\Delta K, \Delta K_{t h}$ )의 경우 상용 $\mathrm{AZ} 31$ 및 $\mathrm{CaO}-\mathrm{AZ} 31$ 에서 각각 3.05 및 $2.72 \mathrm{MPa} \sqrt{m}$ 로 얻어져, 상용 $\mathrm{AZ} 31$ 이 오히려 높은 $\Delta \mathrm{K}_{\mathrm{th}}$ 를 보였다. 이는 $\mathrm{CaO}$ 가 첨가됨에 따라 인장 특성 및 고주기 피로 저항성은 개선되지만 피로 균열 전파 거동에서는 큰 차이를 나타내 지 않으며 오히려 소폭 낮은 $\Delta \mathrm{K}_{\mathrm{th}}$ 를 가지는 것을 의미한 다. 일반적으로 피로 균열 전파 저항성은 균열 선단부에 작 용하는 국부적인 피로 손상에 의해 결정된다 [27]. 균열 선 단부에 생성되는 슬립 밴드의 슬립 가역성(slip reversibility) 에 따라 피로 손상은 변화하며, 이러한 슬립 가역성은 결 정립 크기 및 적층 결함 에너지(stacking fault energy, $\mathrm{SFE}$ )와 관련이 있다 [27]. 먼저, 결정립 크기가 감소할수록 슬립 가역성은 낮아지기 때문에 특정한 결정면을 따라 벽 개 파괴가 발생하기 쉽다. 그러나, 적층 결함 에너지의 경 우 $\mathrm{AZ31}$ 에 $\mathrm{Ca}$ 가 첨가되면 감소하므로 슬립 가역성을 높 이는 것으로 알려져 있다 [28]. 즉, 결정립 크기와 적층 결함 에너지에 대한 슬립 가역성은 서로 상반되지만 $\mathrm{CaO}$ 가 첨가됨에 감소한 결정립 크기가 피로 균열 전파 거동에 보다 지배적인 영향을 미치는 것으로 예상할 수 있었다.

\section{4. 결 론}

본 연구에서는 $\mathrm{CaO}$ 를 첨가한 $\mathrm{AZ31}$ 의 미세조직, 인장 특성, 고 주기 피로 특성 및 피로 균열 전파 거동에 대하 여 조사하였다. 이와 함께 미세조직적 특징을 기반으로 특 성 변화를 고찰했으며 다음과 같은 결론을 얻었다.

(1) $\mathrm{CaO}$ 를 첨가함에 따라 평균 결정립 크기는 감소했으 며 (AZ31: 4.25 $2.32 \mu \mathrm{m}, \mathrm{CaO}-\mathrm{AZ} 31: 2.42 \pm 1.60 \mu \mathrm{m}$ ), 이와 동시에 불균일한 결정립 분포에서 균일한 결정립 분포 로 변화하였다. 상 분석 결과, $\mathrm{AZ31}$ 은 주로 $\alpha-\mathrm{Mg}, \mathrm{Al}_{8}$ $\mathrm{Mn}_{5}$ 및 $\mathrm{Mg}_{17} \mathrm{Al}_{12}$ 상들로 구성되었으며, $\mathrm{CaO}-\mathrm{AZ31}$ 은 $\alpha-$ $\mathrm{Mg}, \mathrm{Al}_{8} \mathrm{Mn}_{4} \mathrm{Ca}, \mathrm{C} 15$ 상들을 포함하는 것으로 확인되었다.

(2) 인장 시험 결과, $\mathrm{AZ} 31$ 과 $\mathrm{CaO}-\mathrm{AZ} 31$ 의 항복 강도들 은 각각 $206.7 \mathrm{MPa}$ 및 $238.0 \mathrm{MPa}$ 로 측정되어 $\mathrm{CaO}$ 첨가 에 따라 항복 강도가 $15 \%$ 상승하는 것으로 나타났다. 뿐 만 아니라 $\mathrm{CaO}$ 첨가에 따라 연신율 역시 증가하는 것으 


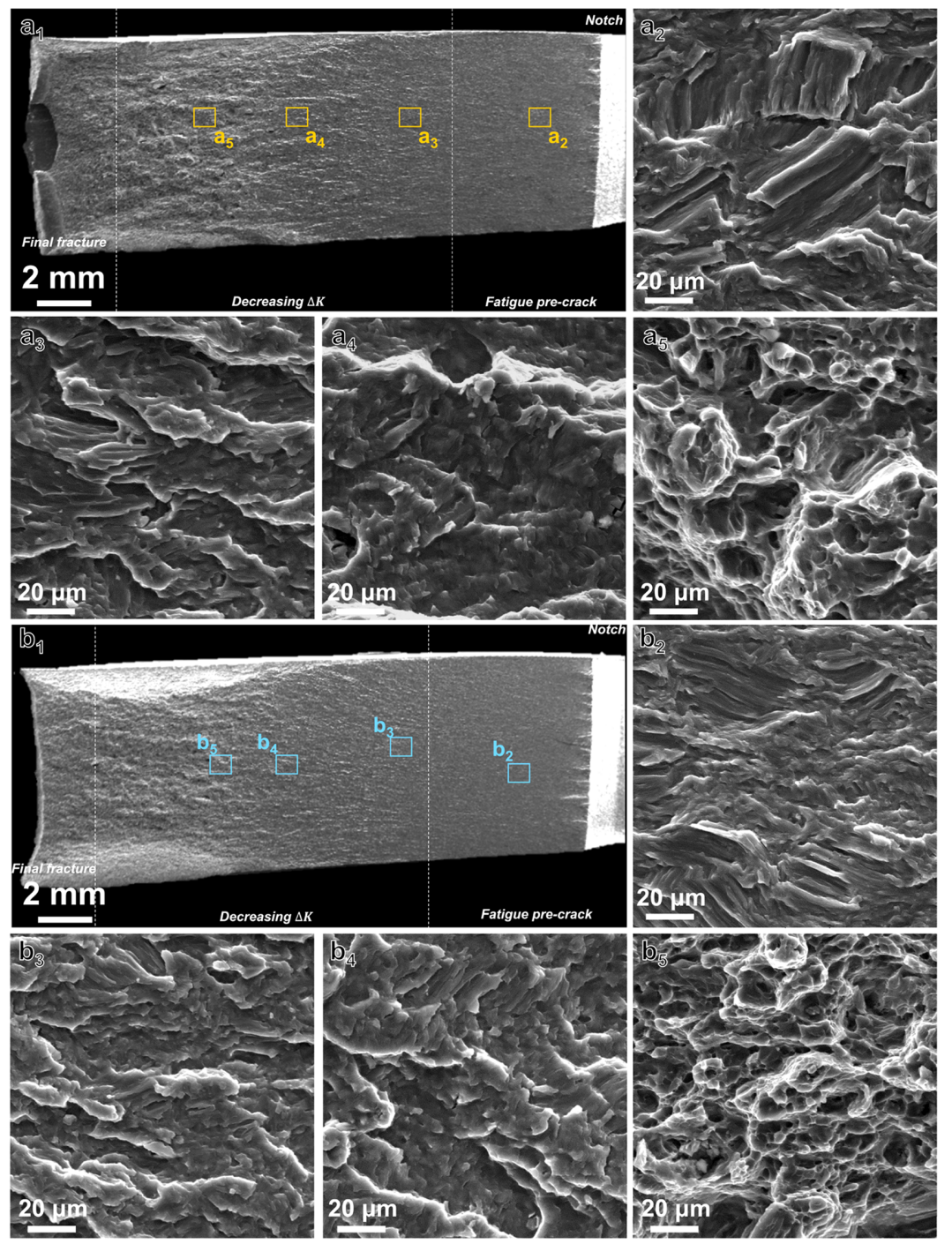

Fig. 10. SEM micrographs showing the fractured surfaces after the da/dN fatigue crack propagation tests; (a) conventional AZ31 and (b) CaO-AZ31 alloys.

로 측정되었으며, 이러한 원인은 변형 쌍정의 생성 거동 차이에 기인하는 것으로 설명되었다.

(3) 고주기 피로 시험 결과, 피로 한도들은 AZ31 및 $\mathrm{CaO}-\mathrm{AZ} 31$ 에서 각각 $140 \mathrm{MPa}$ 과 $160 \mathrm{MPa}$ 로 측정되어 항 복 강도와 동일하게 약 $15 \%$ 피로 저항성이 개선되는 특징 을 보였다. 피로 단면 분석 결과, AZ31의 경우 피로 균열 생성점에서 다량의 변형 쌍정이 관찰된 반면 $\mathrm{CaO}-\mathrm{AZ} 31$ 에 서는 전혀 나타나지 않았다. 이를 통해 결정립 미세화가 피 로 하중이 가해지는 환경에서 변형 쌍정 생성을 억제함에 따라 피로 저항성이 개선되는 것을 알 수 있었다.

(4) 피로 균열 전파 시험 결과, $\mathrm{CaO}$ 첨가에도 불구하고 두
소재들에서 Paris 지수의 차이는 거의 나타나지 않았다. 이와 함께, $\Delta K_{t h}$ 값은 $\mathrm{AZ31}$ 및 $\mathrm{CaO}-\mathrm{AZ} 31$ 에서 각각 3.05와 $2.72 \mathrm{MPa} \sqrt{m}$ 으로 측정되어 오히려 $\mathrm{CaO}$ 첨가에 따라 $\Delta K_{t h}$ 값이 감소하는 특징을 보였다. 이를 통해, $\mathrm{CaO}$ 첨가는 인 장 특성 및 고 주기 피로 저항성을 크게 개선하지만 피로 균열 전파 거동에서는 큰 영향을 미치지 못하는 것으로 확 인되었다.

\section{감사의 글}

본 논문은 인하대학교의 지원에 의하여 연구되었으며 이 
에 감사드립니다.

\section{REFERENCES}

1. International Energy Outlook 2019, Washington (2019).

2. D. Brough, and H. Jouhara, Int. J. Thermofluids 1-2, 100007 (2020).

3. M.-S. Baek, K. Euh, C.-Y. Jeong, and K.-A. Lee, Korean J. Met. Mater. 58, 151 (2020).

4. S. Jayasathyakawin, M. Ravichandran, N. Baskar, C. A. Chairman, and R. Balasundaram, Mater. Proc. 27, 909 (2020).

5. T. Kong, B. J. Kwak, J. Kim, J. H. Lee, S. H. Park, J. H. Kim, Y. H. Moon, H. S. Yoon, and T. Lee, J. Magnes. Alloy. 8, 163 (2020).

6. S. W. Lee, G. Han, T. -S. Jun, and S. H. Park, J. Mater. Sci. Technol. 66, 139 (2021).

7. K. Atik and M. Efe, Mater. Sci. Eng. A 725, 267 (2018).

8. L. Wang, Q. Qiao, Y. Liu, and X. Song, J. Magnes. Alloy. 1, 312 (2013).

9. I.-H. Jung, M. Sanjari, J. Kim, and S. Yue, Scr. Mater. 102, 1 (2015).

10. K. Hantzxche, J. Boheln, J. Wendt, K. U. Kainer, S. B. Yi, and D. Letzig, Scr. Mater. 63, 725 (2010).

11. T. Al-Samman and X. Li, Mater. Sci. Eng. A 528, 3809 (2011).

12. J. Feng, D. Zhang, H. Hu, Y. Zhao, X. Chen, B. Jiang, and F. Pan, Mater. Sci. Eng. A 800, 140204 (2021).

13. A. Suzuki, N. D. Saddock, J. W. Jones, and T. M. Pollock, Act. Mater. 53, 2823 (2005).
14. W. J. Kim, H. W. Lee, J. P. Park, M. G. Kim, and U. S. Yoon, Mater. Des. 30, 4120 (2009).

15. P. Li, B. Tang, and E.G. Kandalova, Mater. Lett. 59, 671 (2005).

16. J.-H. Seo, and S. K. Kim, J. Kor. Fou. Soc. 31, 11 (2011).

17. Y.-K. Kim, M. J. Kim, S. K. Kim, Y. O. Yoon, and K.-A. Lee, Trans. Mater. Proc. 26, 806 (2017).

18. H.-W. Son, J.-W. Lee, and S.-K. Hyun, Mater. Sci. Eng. A 744, 724 (2019).

19. H.-W. Son, T.-K. Jung, J.-W. Lee, and S.-K. Hyun, Mater. Sci. Eng. A 695, 379 (2017).

20. H.-W. Son, J.-W. Lee, and S.-K. Hyun, Mater. Charact. 151, 368 (2019).

21. Y. Zeng, B. Jiang, D. Huang, J. Dai, and F. Pan, J. Magnes. Alloy. 1, 297 (2013).

22. R. Xin, C. Guo, J. J. Jonas, G. Chen, and Q. Liu, Mater. Sci. Eng. A 700, 226 (2017).

23. M. S. Tasi, and C. P. Chang, Mater. Sci. Technol. 29, 759 (2013).

24. F. Zhao, T. Suo, B. Chen, and Y. L. Li, J. Alloy. Compd. 798, 350 (2019).

25. S. W. Lee, S.-H. Kim, and S. H. Park, Korean J. Met. Mater. 56, 699 (2018).

26. M. Li, Q. Pan, Y. Shi, and Y. Wang, Mater. Sci. Eng. A 611, 142 (2014).

27. S. Kim, T. Song, H. Sung, and S. Kim, Met. Mater. Int. (In press). doi: https://doi.org/10.1007/s12540-019-00436-7.

28. U. M. Chaudry, T. H. Kim, S. D. Park, Y. S. Kim, K. Hamd, and J. -G. Kim, Materials 11, 2201 (2018). 